\title{
Social organization and reproductive behavior in southern Ghana
}

Dominic K. Agyeman

John B. Casterline

Population Council

Follow this and additional works at: https://knowledgecommons.popcouncil.org/departments_sbsr-pgy

Part of the Demography, Population, and Ecology Commons, Family, Life Course, and Society Commons, and the International Public Health Commons How does access to this work benefit you? Let us know!

\section{Recommended Citation}

Agyeman, Dominic K. and John B. Casterline. 2002. "Social organization and reproductive behavior in southern Ghana," Policy Research Division Working Paper no. 167. New York: Population Council. 
Social Organization and

$>$ Reproductive Behavior in Southern Ghana

Dominic K. Agyeman 


\title{
Social Organization and Reproductive Behavior in Southern Ghana
}

\author{
Dominic K. Agyeman \\ John B. Casterline
}

Dominic K. Agyeman is Professor of Sociology, University of Cape Coast, Cape Coast, Ghana. John B. Casterline is Senior Associate, Policy Research Division, Population Council, New York.

This research was supported by an award from the National Institute of Child Health and Human Development to the Population Council (R01-HD34524) and by an award from the Rockefeller Foundation to the University of Cape Coast. 


\begin{abstract}
The objective of this research is to examine the association between social organization and reproductive behavior in one setting in sub-Saharan Africa. The particular focus is on the effects of social organization on the diffusion of innovative reproductive ideas and behaviors. Social diffusion is assumed to be strongly affected by patterns of informal social interaction, and these in turn are assumed to be determined in part by the social organization of local communities (gender relations, employment activity, voluntary organizations). The research draws on data collected in six communities in southern Ghana. The analysis reveals a weaker than expected association between the social organization of the communities and key reproductive indicators (fertility preferences, age at first marriage, postpartum practices, use of modern contraception). Closer examination of the six communities suggests that the weak association is explained by the idiosyncratic histories of several of the communities, in particular their histories of health and family planning provision. Explanations for reproductive change that place social organization on center stage must be enlarged to incorporate the potentially powerful influence of community history.
\end{abstract}

This material may not be reproduced without written permission from the authors. For a list of Policy Research Division Working Papers, including those available for downloading in PDF format, see www.popcouncil.org/publications/wp/prd/rdwplist.html. 
In this paper we join together two research traditions that have attempted to explain societal-level variation in fertility. Both traditions have a long heritage and a large literature. The first posits that reproductive behavior is heavily influenced by the social organization and cultural practices of a society. While this proposition can be applied to any society, whatever its cultural heritage or level of income (or, for that matter, level of fertility), perhaps in no region has this proposition held greater sway over research on reproduction than in sub-Saharan Africa. The tradition goes back at least to the seminal volume edited by Lorimer in the 1950s (Lorimer 1954), continuing with much originality in Caldwell's work in the late 1970s (Caldwell 1982), and revived once more in the stimulating set of papers collected by Lesthaeghe (Lesthaeghe 1989) and the ambitious multivolume National Academy of Sciences assessment of the demography of sub-Saharan Africa (NRC 1993). The proposition can be broken into several distinct partssocial organization can be distinguished from cultural practices, and both can be subdivided further-but a common mode of analysis unites the various strands in this research tradition: societal-level variation in reproduction is explained by the imperatives contained in the cultural and social systems that have been passed down through the generations. The key imperatives might concern childbearing itself, or any of the chief proximate determinants of fertility, such as marriage and postpartum behaviors. This school of thought struggles to explain reproductive change. This is not to say that the major theoretical frameworks linking social organization and reproductive behavior cannot accommodate reproductive change, but one must look outside this tradition for a fullfledged theory of why and how reproductive change might occur.

Social change is the main preoccupation of the second research tradition that informs the work in this paper. The innovation diffusion tradition posits that social change can occur as the result of novel ideas, technologies, and behaviors spreading from one social group to another (Rogers 1983). Obviously individuals must perceive that adoption of the innovation will be to their advantage, but cost-benefit assessment that favors the innovation is not by itself sufficient: individuals must be exposed to the innovative ideas, technologies, and behaviors, and ordinarily this requires their introduction from the outside, that is, innovation diffusion. There are several means by which innovations can be introduced into a group. It might occur deliberately through the mass media or 
formal schooling, as has been the case with modern contraception in sub-Saharan Africa and other high-fertility societies in recent decades. Perhaps more interesting from a social scientific standpoint, and more challenging as well, is innovation diffusion through social networks. This channel is comprised of various mechanisms, including informal day-to-day conversation with friends and neighbors, discussion with workmates, and exchanges in formal group meetings. Social networks vary in size and structure from one society to another, and this variation may well have implications for the ease and rapidity of innovation diffusion (Valente 1995). A common argument, to which we return below, distinguishes between homogeneous and heterogeneous networks, with the latter on balance facilitating innovation diffusion. Henceforth in this paper, we use the phrase "social diffusion" to refer to innovation diffusion that occurs through social networks, broadly defined.

It is the link between social organization and social diffusion, in this instance with respect to reproductive behavior, that is our primary interest. The aim is not to put the validity of either research tradition to the test, but rather by joining them to gain insights about how social organization can affect reproductive behavior. Our analytical strategy is comparison of a discrete number of communities in southern Ghana, first characterizing their social organization, then considering how the communities vary in their receptivity to social diffusion, and finally examining covariation of both with indicators of reproductive behavior (fertility and its proximate determinants). Because fertility is declining in Ghana, with increased practice of modern contraception a major contributing factor (Ghana Statistical Service and Macro International 1999; Blanc and Grey 2000), there is good reason to posit that the receptivity of these communities to innovative reproductive behavior will explain much of the observed cross-community variation in reproductive behavior. In linking social organization to social diffusion, we depart from the concerns of Caldwell (1982) and Lesthaeghe (1989), who consider social organizations in relation to modes of production and reproduction; such an approach leads to a theoretical framework for reproductive behavior that relies heavily on economic arguments. In contrast, we focus on the role of social organizations and other social structures as channels of social diffusion.

It should be clear from the preceding paragraphs that we take the view that reproductive behavior is socially determined and not simply an attribute of an individual. 
Both research traditions-social organization and innovation diffusion-make this assumption, whether or not explicitly stated. This means that group membership can have considerable bearing on individuals' fertility decisions. Our approach fits squarely in a theoretical tradition in sociology that is most prominently represented by Durkheim. In keeping with the aim of explaining group-level variation, the analysis that follows is carried out at the community level.

\section{DATA}

We analyze data collected in six communities in southern Ghana: two in the Greater Accra Region (Amanfro and Tubaman), two in the Central Region (Brenu-Akyinim and Frami), and two in the Western region (Abuesi and Komfoeku) (see Figure 1). The six communities were purposely selected for diversity in ecological setting (coastal versus inland), primary economic activity (farming, fishing, trading), ethnic composition (GaAdangbe and Akan) and corresponding kinship (patrilineal and matrilineal), and religion (Christian, Muslim, indigenous). These differences are explored in greater detail below.

Data collection in these sites began in 1994 and has continued to the present. The analysis here draws on three types of empirical materials gathered in the six communities:

Community portrait. In 1994/95 and again in 1998/99, project investigators developed in-depth portraits of the study communities, on the basis of extended stays in each community during which formal and informal interviews were conducted and community activities were observed. The community portraits focus on political organization, principal economic activities and sources of income, social and religious organizations, schools and health services, and fertility-related customs and practices. These portraits achieve our aim of describing key social organizational features of each community.

Organization inventory. In 2000, an inventory of organizations in each community was constructed, through interviews with community members. The intention was to obtain a comprehensive listing of organizations in each community: names, objectives, number of members, and frequency of meeting.

Panel survey. Women of reproductive age (ages 18-50) and their male partners in each community were interviewed at length in late 1998 and subsequently have been reinterviewed at roughly six-month intervals in a "panel survey" design. (This paper makes use of data from rounds 1-3.) The combined survey sample size for the six com- 


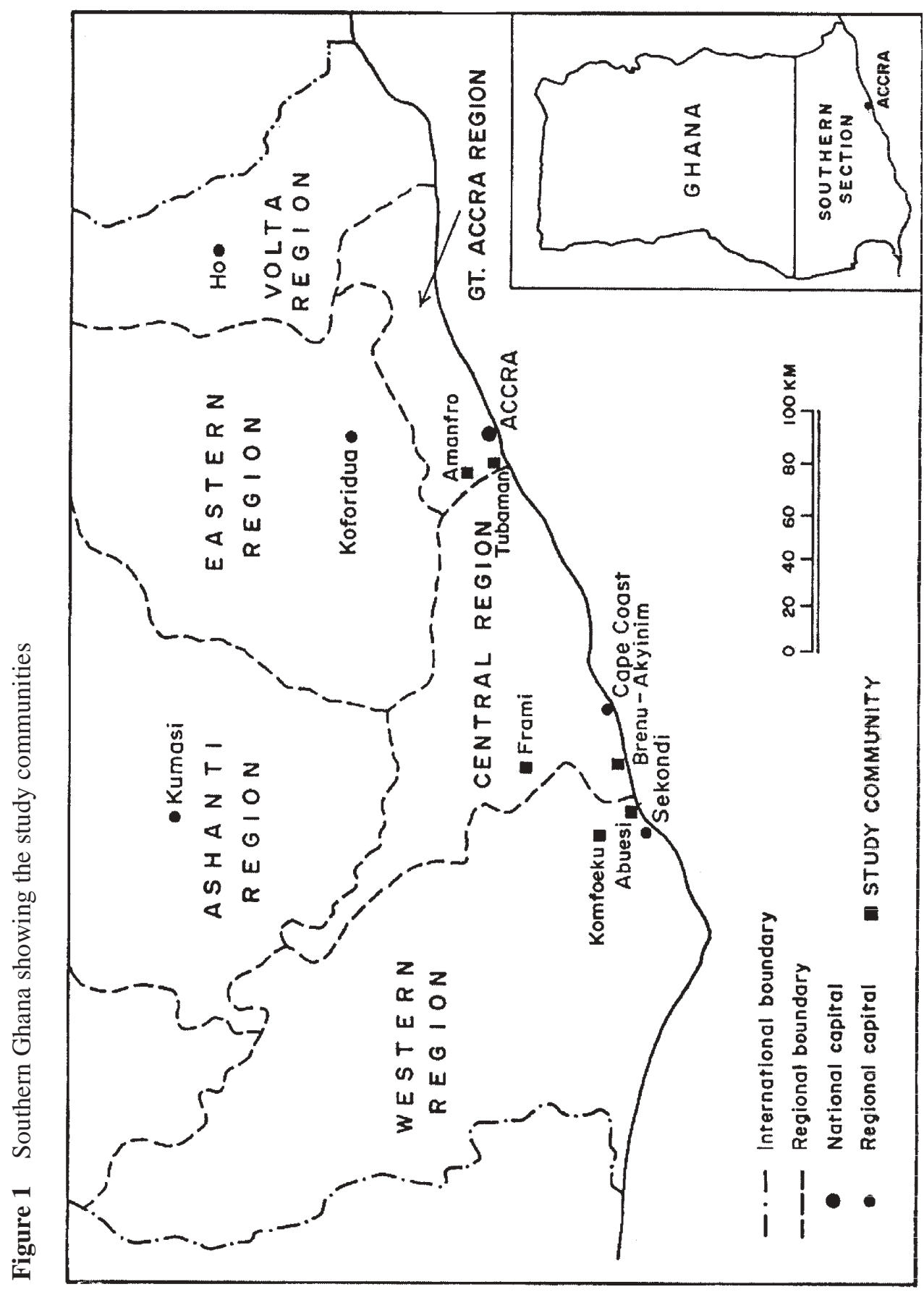


munities is approximately 1,300 women and 700 male partners. Among the topics inquired about are reproductive behavior (including details of the respondent's reproductive career and his/her contraceptive attitudes and practices); attitudes and preferences concerning childbearing and childrearing; socioeconomic characteristics of the respondent and his/her household; knowledge and attitudes about HIV/AIDS; mass media exposure; geographic mobility; and social networks.

As noted above, our analytical approach consists of three stages: a characterization of key social organizational features of each community; a consideration of how these features in turn bear on the receptivity of the communities to social diffusion; and an examination of differentials across communities in reproductive behavior, in light of community differences in social organization and receptivity to social diffusion.

\section{BASIC FEATURES}

The basic features of the six communities are summarized in Table 1. In terms of ecological setting, four of the communities are inland and two coastal. Fishing is a primary economic activity in the two coastal communities, although farming figures importantly in the local economy of Brenu-Akyinim. Judging by the mean number of household possessions (items such as a radio, television, refrigerator, bed with foam mattress, bicycle, and so forth—ten items maximum) and the percentage of households that are electrified, Amanfro and Tubaman are the most prosperous communities, probably because of their proximity to Accra. The educational attainment of women is highest in Brenu-Akyinim, whereas the educational attainment of men is higher in Amanfro and Frami.

There are clear differences among the six communities in their religious composition. Tubaman is almost entirely Muslim, and there is a substantial Muslim minority in Abuesi (about one-quarter of respondents). The progression of Islam into West Africa for the most part stopped short of the coast (Islam, of course, is the dominant religion in many parts of the interior of West Africa), but there are nevertheless some significant Muslim communities along the coast. Among the other four communities, affiliation with orthodox Christian denominations predominates in Brenu-Akyinim, while Pentecostal Christianity predominates in Amanfro. All communities except Tubaman permit indigenous religious practices in addition to Christianity and Islam. 
Table 1 Basic features of the six communities

\begin{tabular}{|c|c|c|c|c|c|c|}
\hline Feature & Abuesi & Amanfro & $\begin{array}{c}\text { Brenu- } \\
\text { Akyinim }\end{array}$ & Frami & Komfoeku & Tubaman \\
\hline & & Greater & & & & Greater \\
\hline Region & Western & Accra & Central & Central & Western & Accra \\
\hline Ecology & Coastal & Inland & Coastal & Inland & Inland & Inland \\
\hline $\begin{array}{l}\text { Primary economic } \\
\text { activity }\end{array}$ & Fishing & Trading & $\begin{array}{l}\text { Farming } \\
\text { Fishing }\end{array}$ & Farming & Farming & Farming \\
\hline $\begin{array}{l}\text { Mean number } \\
\text { of household } \\
\text { possessions }^{\mathrm{a}}\end{array}$ & 3.5 & 4.6 & 3.4 & 2.7 & 3.2 & 5.0 \\
\hline $\begin{array}{l}\text { Percent of households } \\
\text { electrified }^{\mathrm{a}}\end{array}$ & 88 & 85 & 71 & 79 & 74 & 82 \\
\hline \multicolumn{7}{|l|}{$\begin{array}{l}\text { Percent JSS+ } \\
\text { schooling }^{\mathrm{b}}\end{array}$} \\
\hline Women & 27 & 45 & 58 & 49 & 30 & 32 \\
\hline Men & 32 & 79 & 60 & 77 & 62 & 41 \\
\hline $\begin{array}{l}\text { Religious } \\
\text { affiliation }^{\mathrm{c}}\end{array}$ & $\begin{aligned} \mathrm{OC} & =29 \% \\
\mathrm{PC} & =37 \% \\
\mathrm{M} & =24 \%\end{aligned}$ & $\begin{array}{c}\mathrm{OC}=17 \% \\
\mathrm{PC}=68 \% \\
\mathrm{M}=7 \%\end{array}$ & $\begin{array}{c}\mathrm{OC}=71 \% \\
\mathrm{PC}=19 \% \\
\mathrm{M}=2 \%\end{array}$ & $\begin{aligned} \mathrm{OC} & =50 \% \\
\mathrm{PC} & =41 \% \\
\mathrm{M} & =0 \%\end{aligned}$ & $\begin{aligned} \mathrm{OC} & =38 \% \\
\mathrm{PC} & =46 \% \\
\mathrm{M} & =0 \%\end{aligned}$ & $\begin{array}{l}\mathrm{OC}=4 \% \\
\mathrm{PC}=6 \% \\
\mathrm{M}=90 \%\end{array}$ \\
\hline $\begin{array}{l}\text { Primary } \\
\text { ethno-linguistic } \\
\text { group }\end{array}$ & Akan & Ga-Adangbe & Akan & Akan & Akan & Ga-Adangbe \\
\hline
\end{tabular}

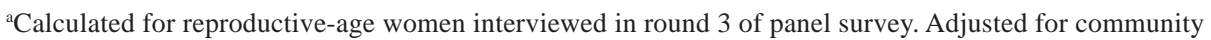
differences in age and marital status (through poisson and logit regressions).

${ }^{b} \mathrm{JSS}+=$ junior secondary schooling completed. Calculated for reproductive-age women and their male partners interviewed in round 1 of panel survey. Adjusted for community differences in age and, for women, marital status (through logit regression).

${ }^{c}$ Percentage distribution of reproductive-age women interviewed in round 1 of panel survey.

$\mathrm{OC}=$ Orthodox Christian; $\mathrm{PC}=$ Pentecostal Christian; $\mathrm{M}=$ Muslim. The residual category consists of syncretic and traditional groups.

Source: Community portraits; panel survey

Finally, ethnolinguistically four of the communities are comprised primarily of Akan-speaking people, one is predominantly Ga (Amanfro), while the sixth is Adangbe (Tubaman). The Ga and Adangbe are usually classified together as Ga-Adangbe because of their very close ethnolinguistic affinity. Ethnolinguistic affiliation essentially determines the dominant lineage rules in each community, which in turn have repercussions for gender relations and other factors bearing on reproductive behavior (Lesthaeghe 1989). Hence the ethnic composition of the communities is a critical element in the argument developed below. 


\section{SOCIAL ORGANIZATION}

\section{Kinship and Gender Relations}

In these six communities the family, clan, and lineage are central to the identity and well-being of the individual. Generally, the four Akan communities follow the matrilineal inheritance system, while the two Ga-Adangbe communities follow the patrilineal system. Yet among the Akan, certain positions such as the Asafohene ${ }^{1}$ and the chief priests of the gods are inherited patrilineally. Within the two Ga-Adangbe communities, the residents of Tubaman stress the principles of patrikin and male dominance more highly than the residents of Amanfro.

In the eyes of the people of Tubaman, a child is first of all a lineage member, and one of the chief purposes of socialization is to produce a loyal and worthy addition to the lineage. The residents of Tubaman, therefore, practice a system of patriarchy and patrilocality (coresidence of husband and wife after marriage) that ensures male dominance over females. Islam reinforces the patrilineal strains in the Ga-Adangbe culture (see Lesthaeghe 1989: 34). In the community portrait of Tubaman, it is reported that decisionmaking about most matters is strictly male-dominated, with the exception of those areas of exclusive concern to women. (For instance, when the women meet alone, as in the 31st December Women's Movement, they are allowed to assume leadership roles.) During worship, only males are allowed to play leadership roles; women are forbidden to stand before men and preach. In every home the man is supposed to be the head, with adult women supporting him as deputies, his sons following in authority, and his daughters having the least power.

This male dominance in the family and community in Tubaman contrasts sharply with the position of men in the nearby market town of Amanfro and in the four farming and fishing Akan-speaking communities. It is often the practice in Amanfro, as in other Ga-Adangbe communities, that after marriage the husband continues to live in the men's compound of his father and the wife in the women's compound of her mother. Men take their meals together in the men's compound, although the food may have come from wives residing in several women's compounds. Under this arrangement, neither partner is under the strict control of the other for most of the day. Not only do these kinship 
practices of the people of Amanfro have implications for power and authority in marriages (for example, the degree to which spouses share interests and resources), they also have implications for social interaction patterns. There is less opportunity for exchange of information between spouses and more opportunity for spouses to interact with other persons. In general, Ghanaians interact most frequently with other residents of the same compound (this is documented by the panel survey data on social network partners); hence the traditional Ga-Adangbe residence pattern provides more opportunity for nonspousal social interaction than would be the case were the spouses coresiding. We return to this point below.

However, there is evidence of change in the customary coresidence patterns in Amanfro, suggesting that the pattern of separate residence for spouses may have begun to break down. Today one observes many nuclear-family households composed of a husband, his wife, and their unmarried children. A related feature of the Amanfro traditional family system that seems to be changing is the merging of households into a more inclusive segment. Fortes (1949) termed this the "effective minimal lineage." In traditional Ga-Adangbe society, a man had little jural, ritual, and economic authority while his father was alive, because the household of the man and his children was submerged in a more inclusive segment with the man's father as the head. In recent decades, this full merging of households is rare, although most compounds are still headed by the fathers and male elders of the patrilineage. Today the authority of the senior male is more limited in reach, because an increasing fraction of households are organized around the conjugal pair. In Amanfro as compared to Tubaman, women are more able to exert authority in their families by virtue of being the main breadwinners of the household. In contrast to Tubaman, in Amanfro decisionmaking is not monopolized by men, despite the fact that the people of both communities are patriarchal in their kinship system and in many practices concerning family matters.

The Akan communities are influenced by an entirely different set of traditional kinship rules. In Akan society descent is primarily matrilineal, although patrilineal descent is the norm for certain positions, for example the Asafo executioners (members of the Asafohene) and priests. For this reason, some scholars prefer to classify Akan society as based on bilateral descent (e.g., Lesthaeghe 1989: 39). The interplay of these two 
systems makes for distinctive spousal roles and decisionmaking authority in Akan communities. Wives are expected to reside with their husbands after marriage. This may be neolocal residence, but is often virilocal or patrilocal. The residential arrangement and matrilineal descent combine to balance spousal relations within marriage. The household organization is centered on the conjugal pair, with the husband normally regarded as the head. Although in this position the husband has some decisionmaking authority, he is expected to consult his wife on most family issues, with her views exercising an important influence on decisions and actions. Hence, while the man is regarded as the ultimate authority, the norms and rules of Akan society encourage negotiation and bargaining between spouses.

The links between kinship system and postpartum practices should be noted. In the strict patriarchal system characterizing Tubaman, the new mother does not reside in her kin's home during the postpartum period, but rather remains with her husband. In contrast, in the matrilineal system of the Akans, a woman can return to her parental kin during the postpartum period, and indeed births may be delivered away from the husband's compound. The loose patrilineal system of the Ga-Adangbe in Amanfro does not appear to include any hard and fast rules about a woman's residence during pregnancy and the postpartum period, although by the logic of residential arrangements the new mother would, more often than not, be found in her kin's compound.

Other aspects of kinship that bear directly on reproduction do not vary in their essential features among the six communities. Polygamous marriage is allowed and practiced in all study communities. In the panel survey data, the proportion of women in polygynous unions ranges from 41 percent in Tubaman to 13 percent in Frami. The prevalence of polygamous marriage is somewhat higher in the two Ga-Adangbe communities, which are also somewhat more prosperous, judging by the indicators in Table 1. (An additional factor in the case of Tubaman is that Islamic law permits polygyny.) In general in these communities the choice of a mate is not a matter for the individual alone: parents and other senior agnates still exercise some control over matchmaking, for marriage not only unites the couple, it also establishes a new and important relationship between their respective lineages. ${ }^{2}$ The primary rationale for marriage is the production of children, and it is the wish of every member of the family and the descent 
group to maintain the strength of the lineage and the clan. Thus infertility in particular puts women at increased risk of divorce and makes it more likely that her husband will take another wife. This puts much pressure on women to reproduce, and the community portraits describe how women consult herbalists, spiritualists, and traditional priests to assist them in conceiving and bearing children.

From the discussion so far, three distinct types of male-female relationships can be discerned in the six communities under study. The Tubaman (or Islamized) type of relationship is characterized by male dominance over females. This relatively extreme case of patriarchy in West Africa is bolstered by Islamic law. Decisionmaking, both public and private, lies in the hands of men. Farthest removed from this among the study communities is the type of male-female relationship found in Amanfro. Although descent is reckoned patrilineally, this is not accompanied by a forceful patriarchy. Women are not under the strict control of their husbands, and therefore may make independent decisions. The relative weakness of the conjugal bond is the most salient characteristic of this system. The third type of relationship is represented by the Akan bilateral system that is traditional in the other four communities. The Akan relationship may be described as one of partnership rather than male dominance (Tubaman) or loose relationship (Amanfro).

The classification of the six communities in terms of the gender relations that can be expected to result from the traditional kinship system is as follows:

\begin{tabular}{ll} 
Community & Gender relations \\
\hline Abuesi & Complementary \\
Amanfro & Independence \\
Brenu-Akyinim & Complementary \\
Frami & Complementary \\
Komfoeku & Complementary \\
Tubaman & Male control \\
\hline
\end{tabular}

\section{Voluntary Organizations}

We now investigate the role of voluntary organizations in the six communities, as measured in the organization inventory. Undoubtedly some of the voluntary organiza- 
tions listed in the inventory are actively pro- or antinatalist, and this in itself may influence members' reproductive attitudes and behaviors, thereby contributing to differences among the communities in reproductive behavior. For this reason, we take note of what the inventory indicates about the fertility-related activities of the organizations, although we regard this evidence as merely suggestive. Our main purpose here is to assess how the communities vary in the number of voluntary organizations and their distribution by type (e.g., religious versus political). Of particular concern is how the voluntary organizations might bear on gender systems, as described in the previous section, and on the patterns of social interaction that we consider later.

Local-level organizations have captured the attention of many in the field of international development. Taking off from the concept of "social capital" developed by Bourdieu and Coleman in the 1980s (Coleman 1988, 1990; Bourdieu and Wacquant 1992), the belief that development initiatives are more likely to succeed in communities that are rich in voluntary organizations has become popular. The argument is not that voluntary organizations engage in deliberate activities in support of development initiatives, although indeed this may occur and contribute to an observed association between community development and the prevalence of such organizations. Rather, the hypothesis is that the social bonds nurtured by voluntary organizations constitute a resource ("social capital") that makes community members more receptive to development initiatives and better positioned to maximize their benefit from such initiatives. This is so for multiple reasons, according to social capital theorists, including the social cohesion and trust that voluntary organizations tend to nurture, their capacity to motivate individuals to pursue collective goals rather than private self-interest, and the channels for social diffusion that these organizations provide. It is the last mechanism that is of particular relevance to this study. In testing the social capital argument, empirical studies have related the density of local voluntary organizations to the success of development initiatives (e.g., Narayan and Pritchett 1999). The present study adopts the main hypothesis from social capital theory, namely that a larger number of voluntary organizations in a community should be associated, ceteris paribus, with more rapid change in health and reproductive behaviors. However, we are mindful of the opposite argument, that a higher density of organizations can present an obstacle to change (as pointed out, for example, by Portes and Landolt 1996). Vital and 
respected organizations and their leaders can either promote or obstruct the acceptance of innovative ideas, technologies, and behaviors. By opening or constraining the channels for communication, they may accelerate or retard the pace of innovation. Because the social capital effect is not unambiguously unidirectional, it is all the more important to conduct empirical studies of the association between social capital indicators (such as the density of voluntary organizations) and community change (in this instance, adoption of innovative reproductive behaviors).

Our inventory yielded an extensive list of organizations in each community. For purposes of this paper, these organizations have been classified under seven categories (see Table 2): cultural, religious, occupational, political, educational (school-related), philanthropic/welfare, and health/family life education. Several of these major catego-

Table 2 Number of organizations, by community and type of organization

\begin{tabular}{|c|c|c|c|c|c|c|}
\hline $\begin{array}{l}\text { Type of } \\
\text { organization }\end{array}$ & Abuesi & Amanfro & $\begin{array}{c}\text { Brenu- } \\
\text { Akyinim }\end{array}$ & Frami & Komfoeku & Tubaman \\
\hline Cultural & - & 1 & - & - & - & - \\
\hline \multicolumn{7}{|l|}{ Religious } \\
\hline Christian & 10 & 11 & 8 & 8 & 16 & - \\
\hline Muslim & - & - & - & - & - & 3 \\
\hline \multicolumn{7}{|l|}{ Occupational } \\
\hline Farming & - & - & 3 & 1 & 1 & 1 \\
\hline Fishing & 1 & - & 1 & - & - & - \\
\hline Trading & - & 1 & - & - & - & - \\
\hline Others & 1 & 3 & - & 1 & 1 & - \\
\hline \multicolumn{7}{|l|}{ Political } \\
\hline Modern & 4 & 3 & 1 & 2 & 2 & 3 \\
\hline Traditional & 1 & 1 & 1 & 1 & 2 & 0 \\
\hline $\begin{array}{l}\text { Educational } \\
\text { (school-related) }\end{array}$ & 3 & 4 & 2 & 2 & 1 & 2 \\
\hline Philanthropic/welfare & 2 & 2 & - & 1 & - & 2 \\
\hline \multicolumn{7}{|c|}{ Health/family life education } \\
\hline Traditional & - & - & - & 1 & - & - \\
\hline Modern & 1 & - & - & - & - & - \\
\hline Total & 23 & 26 & 16 & 17 & 23 & 11 \\
\hline
\end{tabular}

Source: Organization inventory. 
ries have been further divided. Within the religious category, Christian and Muslim organizations are distinguished. (Incidentally, no traditional religious organizations were identified, although traditional religious practices are reported in all communities except Tubaman.) The occupational category has been further divided into farming, fishing, trading, and others (hairdressers, drivers, etc.). In addition, modern and traditional political organizations are distinguished, in recognition of the fact that whereas modern political organizations have nationwide links and functions, traditional political organizations are local institutions. Finally, a distinction between traditional and modern health organizations is drawn, on the assumption that their reproductive health values and practices will often differ, with traditional organizations more likely to be pronatalist and modern health organizations more likely antinatalist.

Counts of the number of each type of organization, by community, are presented in Table 2. The number of organizations ranges from a high of 26 in Amanfro to a low of 11 in Tubaman. ${ }^{3}$ Religious organizations represent only about one-quarter of the organizations reported in Tubaman, but in the other five communities they are by far the most common type. This should not be interpreted as evidence that religion holds less sway over individuals' lives in Tubaman; on the contrary, as noted earlier Tubaman is a Muslim community, with Islam exerting a dominating influence on values and practices in all realms of life. Indeed, our community portrait indicates that the people of Tubaman do not admit of values and practices that are contrary to Islamic law. In short, there is less rationale for religious organizations per se in Tubaman, because even without such organizations religion is a pervasive presence in community life. No other community is as religiously homogeneous as Tubaman, as documented in Table 1. In the other five communities, therefore, a plethora of religious organizations (as many as 16 in Komfoeku) offer community members a means to observe and celebrate their particular faith with cobelievers.

It is also evident in Table 2 that all the communities except Tubaman have a traditional political organization as a complement to the chieftancy system and modern political organizations (the latter including the unit committee or town development committee, both common locally throughout Ghana). One traditional political organization, found in all sites except Tubaman, is the Asafo Company, which acts as both a secular and sacred organization. Members of the Asafo are traditional village soldiers, guarding and protect- 
ing the people both physically and spiritually. The absence of this organization in Tubaman again reflects the pervasive influence of Islam in that community.

All six communities have educational organizations. The most common are the parent-teacher association (PTA) and the school management committee. Given our eventual aim of explaining variations in reproductive behavior, gender relations are of interest to us. The information contained in the organization inventory permits classification of the organizations in terms of the sex composition of their membership. Often this is clear from the organization's name: for example, the Jihad Women's Movement, the Assemblies of God Women's Ministry, and the Methodist Women's Fellowship are exclusively for women, whereas both men and women participate in the African Faith Tabernacle, the Methodist Youth Fellowship, and the Catholic Choir. From the membership lists in the organization inventory, often incomplete, it is also possible to determine whether the membership is of mixed or single sex. On the basis of this information, Table 3 shows the distribution of voluntary organizations according to their sex composition.

The majority of organizations are mixed-sex in all communities except Tubaman, where roughly half (5 out of 11) are mixed. In Abuesi, Amanfro, and Frami, about threequarters of the organizations have both men and women as members. Among the singlesex organizations, female organizations tend to be more common, although once again Tubaman is the exception.

As indicated above, the organization inventory contains minimal information on whether or not each organization engages in fertility-related activities. It is plausible that these organizations exercise influence on the views of their members, and hence that organizations whose activities, programs, or objectives include reproductive ideas and behavior would have an impact on the reproductive attitudes and behavior of their members. This effect might be positive or negative, depending on the messages conveyed by the organization. As it happens, organizations reported in the inventory are primarily antinatalist in their emphasis, which itself may be revealing of a less than comprehensive measurement of the full range of relevant activities.

For now, we simply report the number of organizations that have fertility-related programs or objectives. The counts are as follows: Komfoeku, 5 (out of 23); Abuesi, 4 (out of 23); Amanfro, 1 (out of 26); Frami, 1 (out of 17); Brenu-Akyinim, 0 (out of 16); 


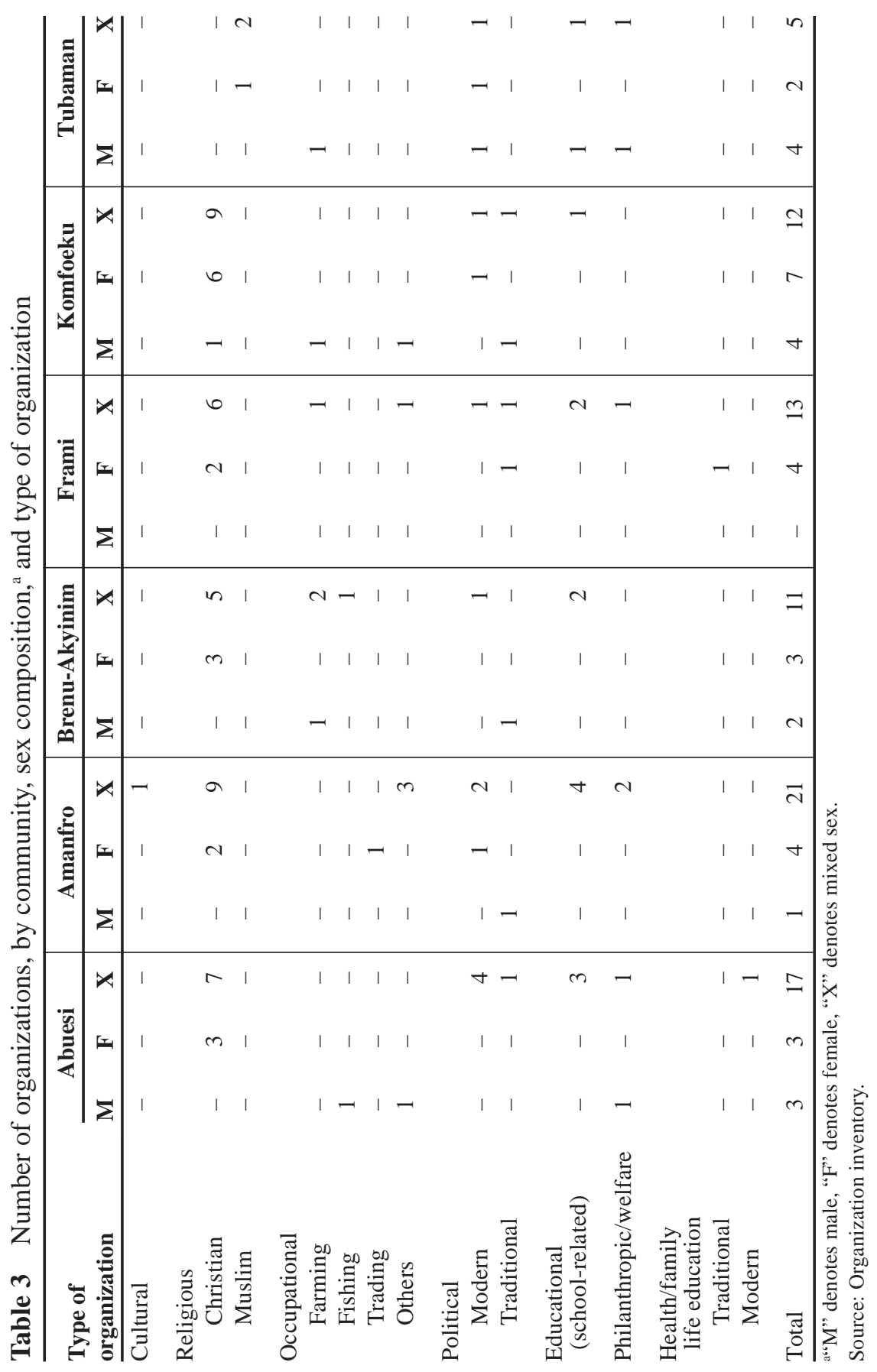


Tubaman, 0 (out of 11). It is, then, a small minority of organizations for which such activities are reported. Of the four organizations in Abuesi, two are women's Christian groups, one is a mixed-sex Christian group, and the fourth is a mixed-sex modern health/ family life education club. All five organizations in Komfoeku are Christian organizations, with four being women's groups and the fifth a mixed-sex group. Clearly, the common belief that religious organizations are less likely to promote antinatalist than pronatalist attitudes and behaviors is not borne out by the information in the organization inventory.

In summary, voluntary organizations are numerous, with only Tubaman lagging in the density of organizations. Religious organizations are most common, followed by political organizations; the majority of these organizations have mixed-sex membership; and only a few of the organizations have activities, programs, or objectives that aim at educating or influencing their members about reproductive behavior.

\section{PATTERnS OF Social InTERACTION}

The second major research tradition informing this paper is the literature on social diffusion. According to theory and empirical studies, one process through which social change occurs is the diffusion of ideas, technologies, and behaviors from one social group to another (Rogers 1983). There are various channels for social diffusion, including the mass media, agents of organized interventions (school teachers, health workers, Christian missionaries), and, of most interest in this analysis, informal social interaction. The hypothesis is that through informal social interaction-with kin, neighbors, friends, workmates-women and men are exposed to new reproductive attitudes and practices (Montgomery and Casterline 1998; Casterline 2001b). The extent of such exposure, in turn, is a consequence of individuals' social interaction patterns, and more specifically what are commonly termed "social networks."

In southern Ghana at present, it is plausible that the key issue concerning social networks, from the standpoint of their efficacy in facilitating (or hindering) the social diffusion of innovative reproductive attitudes and behaviors, is the extent to which they expose individuals to persons from a diversity of social groups (as defined by ethnicity, religion, educational attainment, social class, age, and so forth). Of particular signifi- 
cance is whether individuals' social networks contain persons outside the community, thereby providing a channel for innovative ideas and behaviors to enter the community. Following established theory on social diffusion (with roots in Granovetter's seminal 1973 article), we distinguish "heterogeneous" from "homogeneous" networks, the former being the more diverse in their membership (in terms of basic social attributes). Homogeneous networks are assumed to be more insulated and more likely to support prevailing social norms and practices than to challenge them. In contrast, heterogeneous networks are more likely to offer their members an opportunity to consider a wider range of options for their personal behavior and a reduced pressure to conform to prevailing community norms. In short, heterogeneous networks are more likely to promote social diffusion (Watkins 1991; Kohler et al. 2001).

To this basic hypothesis, appealing in its logic and simplicity, must be added an important qualification (Valente 1995). The hypothesis as stated explains why innovations might enter some communities more easily, and sooner, than other communities. The introduction of an innovation can be viewed as the first stage of social diffusion, and perhaps is the primary determinant of the pace of social change. However, the rapidity with which an innovation spreads within a community is another matter. Within-community diffusion should be more rapid where the patterns of communication are such that a large fraction of members soon learn about the innovation, and where social norms can more quickly adapt to the new ideas, technologies, or behaviors. It is plausible that social interaction patterns in homogeneous communities are more conducive to within-community social diffusion (Valente 1995; Casterline 2001a). The more constraining social pressure assumed to characterize homogeneous communities can obstruct social change, but ironically it can also facilitate such change. A more elaborate hypothesis, then, is that innovations gain a foothold sooner in heterogeneous communities, but once established accumulate adherents more rapidly in homogeneous communities. If, then, one is examining the prevalence of innovative attitudes and behaviors - use of modern contraception, for example-it is not entirely clear whether at any particular date the prevalence should be higher or lower in heterogeneous as compared to homogeneous communities.

For this analysis, we favor the basic network hypothesis, namely that heterogeneous social networks are more conducive to social diffusion. The primary justification 
for retaining this hypothesis is that in southern Ghana reproductive decisions are regarded as essentially private matters, almost entirely within the province of reproductive-age couples and their immediate kin. Hence there appears to be less potential for the positive reinforcement of innovative decisions that homogeneous communities can more effectively offer. However, social norms and pressures are by no means irrelevant in this setting, and we will remain mindful of the qualification articulated in the previous paragraph. This qualification will assist our interpretation of some cross-community variation in innovative reproductive behavior that is otherwise puzzling.

The task now is to characterize the six study communities according to patterns of social interaction, that is, the typical structure of social networks, separately for men and women. To this end, we consider three clusters of variables: (1) gender systems and male-female relationships; (2) the nature of economic activity in each of the communities, on the assumption that economic activity is a primary factor structuring patterns of social interaction; and (3) individuals' geographic mobility and social networks.

Beginning with gender systems and their hypothesized effects on network types, these have far more bearing on the social networks of women than of men, because none of the systems constrain men to any meaningful extent. Everything else being equal, women's social networks should be relatively heterogeneous in communities characterized by gender independence, as in the Ga-Adangbe patrilineal system found in Amanfro. Women in Amanfro need not ask for permission or concurrence of their spouses when making decisions, even if those decisions have implications for the immediate family. Less heterogeneous, but still placing only limited constraints on women, is the system of "complementary" gender relations found in the Akan communities, with their bilateral reckoning of descent. Finally, in Tubaman, with its strongly patriarchal kinship system and male-controlled gender relations, women are least free to circulate and form social relationships of their own choosing; hence social networks are expected to be homogeneous. However, because of the hierarchical decisionmaking power wielded by men in Tubaman, the qualification to the network hypothesis noted above- - that withincommunity social diffusion can occur more rapidly in tightly knit communities-may well apply here. In short, the implications of the gender systems for women's social networks are clear: the most heterogeneous networks are in Amanfro, the most homogeneous are in Tubaman, and the Akan communities fall somewhere in between. 
There is substantial diversity among the six communities in the prevailing types of economic activities and the extent to which these encourage social mixing. We now describe the principal economic activities in each community and the implications for social networks. Because of the predominance of trading in Amanfro, men and women here are likely to have more contact with persons outside the community than residents of the other five communities. In particular, women in Amanfro trade at nearby Kasoa and the more distant Mankesim markets, both of which are on the main Accra-Cape Coast trunk road and attract people from several regions of Ghana. They also trade in Accra. The daily commuting of the residents of Amanfro between Kasoa, Mankesim, and Accra exposes them to diverse groups of people and information. Indeed, the community portrait for Amanfro notes that traders have received information about modern contraception from market conversations with other traders and conversations with "self-proclaimed doctors" and "nurses" who come to the market to sell drugs, including contraceptives.

The residents of Tubaman, too, engage in trade. In contrast to Amanfro, however, agriculture is the main source of livelihood for households in Tubaman. The norm is for a husband and wife to farm together, and for the woman to perform the additional task of selling the produce. Marketing the produce brings the women of Tubaman into contact with other farmers and residents of the nearby market town of Kasoa, and Accra as well. For this reason, the extracommunity social exposure of Tubaman women may approach that of Amanfro women, despite the Islamic norm of social seclusion of women in the former. If economic activity were the only criterion, then one might posit that social networks in Tubaman are nearly as heterogeneous as those in Amanfro.

The economic activities of the residents of Frami and Komfoeku demand far less extracommunity social interaction. As in Tubaman, the main occupation in these communities is farming, but a larger fraction is subsistence farming for household use. Wives do not travel regularly to markets to sell produce; rather, they process farm produce for domestic use and for limited sale in the community. Much of this will be traded using the barter system. There is very little money in the system and, for that matter, there is very little exchange and contact between the people and the outside world. This system of economic activity on balance nurtures homogeneous social networks.

The story is much the same for Brenu-Akyinim, although economic activity there is not as self-contained within the community as is the case in Frami and Komfoeku. 
Brenu-Akyinim is a coastal settlement, with farming and salt mining being the leading economic activities. A minority of Ewe migrants engage in fishing. The farmers engage in subsistence farming, grow food for home consumption, and also grow cash crops for marketing. Women engage in food preparation and the sale of salt and pineapple. Recently an effort has been made to promote pineapple production for export. In short, economic activities in Brenu-Akyinim provide community residents with a limited form of social interaction with persons from outside the community.

While both Brenu Akyinim and Abuesi are coastal settlements, only in the latter is fishing the main economic activity. Men catch fish and women are fish smokers and/or fish mongers. This work brings women into contact with persons from other communities, especially with women who come to the community to buy fish or with women they meet in the market in nearby communities or occasionally in more distant cities (Sekondi-Takoradi and Cape Coast). In addition to the fish industry, Abuesi has been introduced to new economic activities and extracommunity social interaction as a result of the construction and installation of a thermal plant in the adjacent town of Aboadzi. One finds in Abuesi a wide range of economic activities, including carpentry, blacksmithing, dressmaking, hairdressing, and food preparation. Economic activity in Abuesi, hence, leads to more heterogeneous social networks than in the other three Akan communities.

We conclude this section by examining panel survey data on geographic mobility and social networks (see Table 4). Two indicators of geographic mobility are presented: the percentage of respondents born in the community and the percentage who visited a city (Accra, Kumasi, Takoradi, or Cape Coast) at least once per month on average since the previous interview (six to nine months for most respondents). Roughly half the respondents in the four Akan communities (Abuesi, Brenu-Akyinim, Frami, and Komfoeku) were born in that community. The fraction is slightly more than one-third in Tubaman, and only one-eighth in Amanfro. Judging from this indicator, the Akan communities are far more insulated than the two Ga-Adangbe communities, Amanfro in particular. Amanfro also is distinctive in the intensity of recent circulation to cities: 80 percent of Amanfro women visit cities at least once a month, whereas the corresponding figure is 50 percent for Tubaman women and lower yet for women in the four Akan communities (nearly 50 percent in Frami, which has easy access via a main road to Cape Coast, and as 
Table 4 Indicators of geographic mobility, mass media exposure, and social interaction patterns, by community ${ }^{\mathrm{a}}$

\begin{tabular}{|c|c|c|c|c|c|c|}
\hline Variables $^{b}$ & Abuesi & Amanfro & $\begin{array}{l}\text { Brenu- } \\
\text { Akyinim }\end{array}$ & Frami & Komfoeku & Tubaman \\
\hline $\begin{array}{l}\text { Percent born in the } \\
\text { community[R } 1, \mathrm{~W}]\end{array}$ & 50 & 12 & 52 & 51 & 58 & 38 \\
\hline \multicolumn{7}{|c|}{$\begin{array}{l}\text { Percent who visited cities }{ }^{\mathrm{c}} \\
\text { once a month or more often } \\
\text { since last interview [R2] }\end{array}$} \\
\hline Women & 20 & 80 & 35 & 47 & 40 & 50 \\
\hline Men & 41 & 89 & 57 & 58 & 77 & 71 \\
\hline \multicolumn{7}{|c|}{$\begin{array}{l}\text { Percent who watched television } \\
\text { twice a week or more often } \\
\text { since last interview [R2] }\end{array}$} \\
\hline Women & 35 & 71 & 42 & 41 & 36 & 37 \\
\hline Men & 50 & 79 & 46 & 44 & 51 & 53 \\
\hline \multicolumn{7}{|c|}{$\begin{array}{l}\text { Percent who had informal } \\
\text { discussions about AIDS } \\
\text { since last interview [R2] }\end{array}$} \\
\hline Women & 15 & 66 & 19 & 55 & 16 & 16 \\
\hline Men & 35 & 83 & 32 & 66 & 35 & 30 \\
\hline \multicolumn{7}{|c|}{$\begin{array}{l}\text { Mean number of network } \\
\text { partners: } \\
\text { Discuss important matters } \\
\text { [R1] }\end{array}$} \\
\hline Women & 4.1 & 3.4 & 3.5 & 3.5 & 2.8 & 4.1 \\
\hline Men & 4.8 & 4.2 & 4.2 & 3.9 & 3.0 & 4.5 \\
\hline \multicolumn{7}{|c|}{$\begin{array}{l}\text { Discuss modern contraception } \\
\text { [R2] }\end{array}$} \\
\hline Women & 1.2 & 2.2 & 1.4 & 1.9 & 0.9 & 1.7 \\
\hline Men & 1.4 & 2.4 & 1.7 & 2.3 & 1.2 & 1.5 \\
\hline \multicolumn{7}{|c|}{ Discuss HIV/AIDS [R3] } \\
\hline Women & 1.5 & 1.4 & 0.9 & 1.6 & 0.6 & 1.2 \\
\hline Men & 1.9 & 2.2 & 1.1 & 1.7 & 0.9 & 1.6 \\
\hline
\end{tabular}

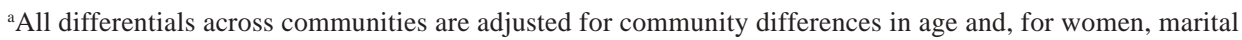
status. The adjustments are carried out through fitting logit or poisson regressions. The statistical significance of variation among communities in each measure has been tested; for all measures shown, the variation among communities is significant at the .001 level.

${ }^{b} \mathrm{R} 1, \mathrm{R} 2, \mathrm{R} 3$ denote panel survey rounds 1, 2, and 3. W and M denote samples of women and men.

'Accra, Kumasi, Takoradi, Cape Coast.

Source: Panel survey. Sample is limited to women interviewed in round 1. Round 3 estimates, for example, are based on respondents also interviewed in round 1 . The men are partners of women interviewed in round 1.

low as 20 percent in Abuesi, despite its relative proximity to Takoradi). The pattern for men is essentially the same, with Amanfro men most likely to have visited cities (almost 90 percent) and Abuesi men least likely (about 40 percent). 
Frequent television viewing (at least twice per week on average) is substantially more likely in Amanfro, for both women and men (third panel of Table 4). There is little variation among the other five communities in this indicator of mass media exposure.

The majority of residents of these communities may have been unaware of HIV/ AIDS when this research project was initiated in the early 1990s. We have no data to confirm or refute this suspicion, but panel survey data collected in 1998 show that awareness of this disease was almost universal by that date-hardly surprising, given the proliferation in the mass media (radio, television, billboards) of advertisements warning of HIV/AIDS and promoting risk-avoidance behaviors. Informal discussion has also undoubtedly contributed to the spread of awareness about modes of infection, and one can view the amount of informal discussion about AIDS as an indicator of the extent to which personal networks are a means for the diffusion of new knowledge and attitudes about health behaviors (fourth panel of Table 4). Judging from the frequency of discussion about AIDS, once again the conclusion is that Amanfro is most exposed to outside influences. Frami follows next, with discussion distinctly less common than in Amanfro but substantially more common than in the other four communities, where discussion is far less likely. In all six communities, men are far more likely than women to report having had conversations about AIDS.

Finally, the panel survey contains detailed measurements of social networks (fifth panel of Table 4). These are conversational networks, defined with reference to different topics in each of the first three rounds of the panel survey: important matters (round 1), modern contraception (round 2), and HIV/AIDS (round 3). Respondents in Komfoeku report the smallest number of conversational partners for all three topics. The communities that rank high, however, vary according to topic: Abuesi and Tubaman for important matters, Amanfro for modern contraception, and Amanfro and Abuesi (and, for women, Frami) for HIV/AIDS. The picture is cloudy, but one might conclude that on average conversational networks are larger in Amanfro and Abuesi and smaller in Komfoeku. On the whole these differentials are consistent with other features of the communities, although it is surprising that conversational networks are not relatively larger in BrenuAkyinim, given the patterns of economic activity and the nearby beach resort, quite popular with Ghanaian and international tourists. 
What can we conclude about community differences in typical social networks? It is difficult to settle on simple characterizations, because the various pieces of information examined here imply somewhat different rankings of the communities. Moreover, in some instances these rankings vary by sex. Even allowing for this complexity, however, the empirical data in hand suggest that social networks are most heterogeneous in the market town Amanfro- - this is the least ambiguous inference-and on balance more homogeneous in the farming communities of Frami and Komfoeku. Abuesi, Brenu-Akyinim, and Tubaman fall somewhere in between. In short, Amanfro stands out as unique-for women in particular because of their exposure to a diversity of individuals in the market and the limited male constraints on their day-to-day mobility.

From this discussion emerges the following classification of the six communities in terms of the heterogeneity or homogeneity of social networks:

\begin{tabular}{ll} 
Community & Social network \\
\hline Abuesi & Heterogeneous \\
Amanfro & Highly heterogeneous \\
Brenu-Akyinim & Somewhat homogeneous \\
Frami & Homogeneous \\
Komfoeku & Homogeneous \\
Tubaman & Somewhat heterogeneous \\
\hline
\end{tabular}

\section{REPRODUCTIVE BEHAVIOR}

We now examine differences among the communities in reproductive behavior, as calculated from the panel survey (see Table 5). Three aspects of reproduction are considered: actual fertility, as indicated by the cumulative number of live births; the main proximate determinants of fertility, specifically nuptiality, postpartum practices (breastfeeding, abstinence), and contraception; and fertility desires. As we argued in the first section of this paper, fertility is declining in Ghana, probably indicative of a decrease in the number of children desired. The primary direct cause of the fertility decline to date, in particular the decline during the 1990s, is increased practice of contraception (Ghana Statistical Service and Macro International 1999; Blanc and Grey 2000). 
Table 5 Indicators of reproductive behavior, by community

Brenu-

Variables Abuesi Amanfro Akyinim Frami Komfoeku Tubaman Significance ${ }^{\mathrm{a}}$

Children ever born ${ }^{\mathrm{b}}$

4.1

3.5

3.9

3.9

4.1

$\mathrm{Men}^{\mathrm{c}}$

6.5

4.4

5.2

4.6

5.2

4.2

6.5

Median age at first

marriage

Women

19.8

20.2

20.1

20.3

20.4

20.2

Men

22.0

24.8

$25.9 \quad 25.6$

25.6

25.7

Breastfeeding:

percent still breast-

feeding at 24 months

postpartum

Women

26

20

32

34

31

40

n.s.

Postpartum abstinence: percent abstaining at 6 months postpartum

Women

55

58

36

48

32

$* *$

Percent who want no

more births ${ }^{\mathrm{d}}$

Women (at 4

living children)

Men (at 5 living

children)

66

55

68

57

55

41

56

36

$*$

Percent currently using

$62 \quad 44$

52

51

56

(36

modern methode of

contraception $^{\mathrm{f}}$

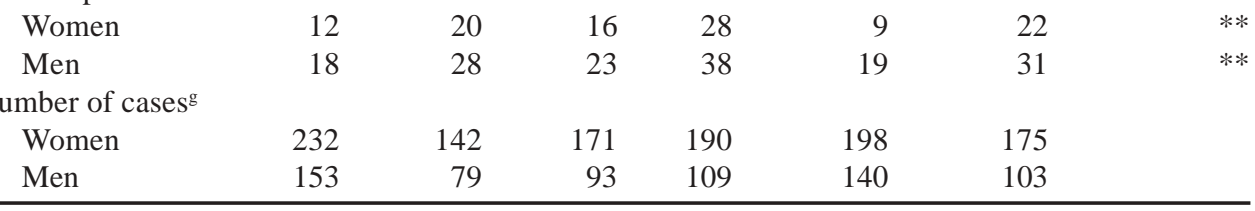

a *denotes significant at .05 level, **denotes significant at .001 level, n.s. denotes not significant.

${ }^{\mathrm{b}}$ Adjusted for community differences in age. The adjustments are carried out through fitting a poisson regression.

'Total births fathered, all partners.

${ }^{\mathrm{d}}$ Fitted percentages, from logit regressions with living children and living children squared. Average of percentages for rounds $1-3$.

ePill, injection, diaphragm/foam, condom, IUD, ligation, Norplant ${ }^{\circledR}$.

${ }_{\mathrm{f}}^{\mathrm{f}}$ Adjusted for community differences in age. The adjustments are carried out through fitting logit regressions.

Average of percentages for rounds 1-3.

${ }^{g}$ Round 1 respondents. Ever-married women; men are current partners of women in sample.

Source: Panel survey (round 1, except where otherwise noted).

In thinking about differences in reproductive behavior in the six communities, it is possible that past differences in marriage and postpartum practices have persisted to the present and might lead to intercommunity differences in fertility rates. Of more 
interest at this point, however, are differences in fertility desires and in the practice of contraception (modern methods in particular), because these are indicative of communities' participation in Ghana's fertility transition.

Before examining community differences in fertility desires and contraceptive practice, we briefly review differentials in fertility, marriage, and postpartum practices (first four panels of Table 5). The number of children ever born is calculated for both women and their male partners. Through multiple wives (serially or simultaneously), men on average have one or two more children than do women. As expected, this sex difference tends to be larger where polygyny is more common (Tubaman and Abuesi) and smaller where polygyny is less common (Frami); Amanfro, where polygyny is relatively common, runs counter to this expectation. Nevertheless, the pattern of community differences is essentially the same for women and men: fertility is lowest in Amanfro and highest in Abuesi and Tubaman.

Because the practice of contraception has not been widespread in these communities in the past, the observed differences in fertility can be attributed to differences in nuptiality and postpartum practices. Interestingly, the timing of entrance to first marriage hardly differs among the six communities (second panel of Table 5): women, and especially men, marry earlier in the fishing community of Abuesi, but residents of the other five communities marry at about the same average age: slightly over age 20 for women, and around age 25 for men. Hence nuptiality patterns in the past do not appear to have contributed to community differences in actual fertility. More intercommunity variation is evident for postpartum practices: breastfeeding (third panel) and abstinence (fourth panel). The average breastfeeding duration is longest in Tubaman, followed by the three Akan farming communities of Frami, Brenu-Akyinim, and Komfoeku, and shortest in Amanfro and Abuesi. Differences in postpartum abstinence, which in these communities probably has more impact than breastfeeding on fertility levels, follow a different pattern. At six months postpartum, roughly twothirds of women are still abstaining in Abuesi, nearly 60 percent in Brenu-Akyinim and Amanfro, roughly one-half in Komfoeku, and only one-third in Frami and Tubaman. The variation across communities in this indicator is surprisingly large. It is difficult, on the basis of this quick overview of selected indicators, to determine how the various proximate determinants, measured and unmeasured (induced abortion), jointly 
account for observed differences among the communities in the average number of births.

Of more central concern here are community differences in childbearing desires and contraceptive practice. We have hypothesized that these facets of reproductive behavior, which are likely to be especially sensitive to the spread of new ideas and behaviors, should be associated with the social organizational features of the communities. The indicator of fertility desires chosen for this analysis is the percentage of respondents who wish to terminate childbearing, shown separately for men and women (fifth panel of Table 5). This desire is evaluated at four living children for women and at five living children for men. For contraception, the indicator is the percentage using modern methods, shown separately for men and women (sixth panel of Table 5). Because use of modern contraception is the clearly innovative behavior in this setting, as well as the principal impetus for the ongoing fertility transition in Ghana, community differences in this aspect of reproductive behavior are of particular interest.

The pattern of community differences in the fifth and six panels of Table 5 varies by sex. Giving more weight here to women, we propose the following ranking of the six communities according to fertility desires and use of modern contraception:

\begin{tabular}{lll} 
Community & $\begin{array}{l}\text { Desire to } \\
\text { limit births }\end{array}$ & $\begin{array}{l}\text { Use of modern } \\
\text { contraception }\end{array}$ \\
\hline Abuesi & High & Low \\
Amanfro & Moderate & Moderate \\
Brenu-Akyinim & High & Moderate \\
Frami & Moderate & High \\
Komfoeku & Moderate & Low \\
Tubaman & Low & Moderate \\
\hline
\end{tabular}

It is surprising that the rankings are so different for fertility desires and contraceptive use. Among other things, this may reflect the fact that much of the contraceptive use is for birth spacing, rather than for terminating childbearing. Even so, it is curious that the high desire to limit births in Abuesi is accompanied by a low prevalence of modern contraception (suggestive of high unmet need for family planning in that community), and that contraceptive prevalence is moderately high in Tubaman despite the relatively weak de- 
sire to restrict fertility. Contraceptive prevalence is highest in Frami-over one-quarter of women report that they are currently using a modern method-followed by Tubaman and then Amanfro. At the other end, the lowest contraceptive prevalence is found in Komfoeku, followed closely by Abuesi.

\section{Putting the Pieces Together}

We have considered multiple aspects of social organization in southern Ghana (kinship systems, gender relations, social interaction patterns) and juxtaposed them with survey estimates of reproductive behaviors, focusing on those behaviors thought to be driving the ongoing decline in fertility in Ghana: fertility desires and contraceptive use. As it happens, different aspects of social organization lead to different expectations about how reproductive behavior should vary among the communities. Adding further to the challenge of drawing clear conclusions from this analysis, the patterns of reproductive differences vary depending on the reproductive indicator chosen.

Mindful of these complexities, we arrive at the following summary of our separate analyses of social organization and reproductive behavior. We show community differences in patterns of both desired fertility and use of modern contraception, since the two patterns are markedly different. The fertility indicators are expressed in terms of their association with the level of fertility; that is, a high prevalence of desires to stop childbearing and a high prevalence of contraception are both labeled "low" because they should translate into relatively low levels of fertility.

\begin{tabular}{lll} 
Community & $\begin{array}{l}\text { Expected fertility } \\
\text { levels based on } \\
\text { social organization }\end{array}$ & $\begin{array}{l}\text { Observed } \\
\text { fertility patterns } \\
\text { (fertility desires/ } \\
\text { contraceptive use) }\end{array}$ \\
\hline Abuesi & Moderate & Low/high \\
Amanfro & Low & Moderate/moderate \\
Brenu-Akyinim & Moderate & Low/moderate \\
Frami & High & Moderate/low \\
Komfoeku & High & Moderate/high \\
Tubaman & Moderate & High/moderate \\
\hline
\end{tabular}

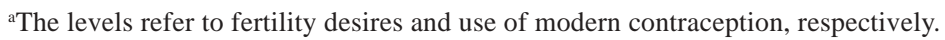
They are formulated in terms of effects on fertility levels: "high" refers to low percentages wanting to stop childbearing or using contraception, whereas "low" refers to high percentages wanting to stop childbearing or using contraception. 
The fit between expected and observed fertility is disappointing. We expected Amanfro to be most advanced in the fertility transition, as reflected in fertility desires and contraceptive practice, but instead it falls somewhere in the middle of the six communities. (Interestingly, in Table 5 Amanfro does show the lowest level of actual fertility, a ranking more consistent with our expectations.) Similarly, Frami and Komfoeku were expected to be less advanced in the fertility transition, and although Komfoeku essentially fulfills this expectation, Frami has a high prevalence of use of modern contraception. Abuesi and Tubaman further confuse the picture: both were expected to show moderate levels of fertility, but this expectation is fulfilled only with respect to modern contraceptive use in Tubaman.

We believe that this unexpected pattern of intercommunity differences in reproductive behavior can be explained, but doing so requires introducing two additional types of information, namely the actions of community leaders and the provision of health and family planning services. Neither of these has figured prominently in our discussion thus far, but they can do much to unravel the mystery of the community differences in fertility. The major anomalies in the differences are that contraceptive use is relatively high in relation to our expectations in Frami and Tubaman, and relatively low in Amanfro. A reading of the community portraits suggests that, for Frami, the explanation may lie in the greater availability of family planning and health services. Frami has a well-functioning health clinic and a drugstore that sells medicines, including contraceptives. In addition, Frami is visited frequently by staff of the Planned Parenthood Association of Ghana (PPAG), as well as government and health personnel from Cape Coast, only 35 kilometers away on a major road. Finally, community members tell of the Frami resident who was sponsored by the village in the early 1990s to undertake formal training in family planning offered by PPAG. The man in question was a member of the town development committee. Since then, he has been organizing family planning discussions with households in the community. These discussions were referred to during focus group discussions conducted in the pilot stage of our project. In short, among the six communities, Frami is perhaps most richly endowed with health and family planning services, and this might well account for its relatively high prevalence of contraceptive use. 
The case of Tubaman is also interesting. The notion of practicing family planning through use of modern contraceptives is relatively new in the community, and is traced by community residents to a specific development. Contraception had been regarded as contrary to Islamic teachings. But the son of the present chief's sister traveled to Saudi Arabia for his university education, and then returned to Ghana with the news that family planning is compatible with Islam. Henceforth family planning could be discussed openly in Tubaman, and contraceptive practice need not be covert. Given the strongly hierarchical structure of social life in Tubaman, this sanctioning of family planning by senior leaders of the community had a larger impact than in most other Ghanaian communities. This fits with our earlier argument that homogeneous communities can be conducive to rapid diffusion of innovative behaviors, because social pressure can be exerted more effectively-with the pressure in this instance coming from community leaders via the strongly hierarchical local power structure. Complementing this factor has been the fairly effective provision of health and family planning services in Tubaman by the health nurse, who holds a weekly Friday clinic in the community. In qualitative interviews, residents tell of women taking their children with them to the Friday clinic, ostensibly to receive medical care for the children but in fact for the purpose of receiving a contraceptive injection.

Finally, we consider the case of Amanfro. The relatively low level of contraceptive practice in Amanfro, as compared to our expectations, remains a puzzle. We note in Table 5 the relative absence of desires to terminate childbearing, suggesting that children are valued more highly in Amanfro than in some of the other communities. One can argue that, among the various ethnic groups in Ghana, the Ga are more pronatalist, with customary practices that encourage women to bear many children being more strongly maintained than is the case in other ethnic groups. Various initiation rites promote early age at first birth and adolescent pregnancy. While the people of Amanfro admit the potential economic costs of having a large number of children, the view persists that large numbers of children are an economic asset in old age. This attachment to childbearing, despite its recognized economic costs (and despite the relatively easy and inexpensive availability of contraceptive methods in the community), perhaps explains why contraceptive prevalence is lower in Amanfro than we 
predicted. This is largely speculation, and clearly further empirical investigation is required to verify this explanation.

\section{CONCLUDING REMARKS}

The overarching objective of this research has been to examine the association between social organization and reproductive behavior. In contrast to most prior research on sub-Saharan African societies with the same objective, we have not focused on those aspects of social organization thought to account for variation in pretransitional reproductive regimes. Pretransitional variation in fertility was probably due primarily to nuptiality and postpartum practices. Rather, our concern lies with how social organization affects the diffusion of innovative reproductive ideas and behaviors. Social diffusion is assumed to be strongly affected by the nature of social interaction patterns, and these in turn are assumed to be determined in part by the social organization of local communities: gender relations, employment activity, and the prominence of voluntary organizations. With this theoretical orientation, we are able to develop explicit hypotheses about how the adoption of fertility-control desires and behaviors (e.g., use of modern contraception) should vary among six communities in southern Ghana.

In the event, the empirical data on fertility obtained in the panel survey does not clearly confirm the hypotheses. This outcome is a disappointment, but we do not regard it as a decisive rejection of the social organization and social diffusion arguments. Rather, we conclude that research which examines a small number of communities must be sensitive to their particularities and idiosyncrasies. Two of the study communitiesFrami and Tubaman-show relatively high prevalence of contraceptive use, contrary to expectations, and this can be explained by circumstances specific to the recent history of each community (the actions of health workers in both communities, the formal discussions organized by the PPAG-trained man in Frami, and the endorsement of family planning by the religious leadership in Tubaman). Another community-Amanfroshows lower-than-expected prevalence of contraceptive use, and this may be explained by the continued attachment to pronatalist customary beliefs and practices. A statistical demographer might view this as a "small-sample" problem: when the sample consists of merely six communities, historical circumstances specific to one or two communities can exert a strong influence on the results. 
A general conclusion is that an explanatory framework which places social organization on center stage must be enlarged to incorporate the potentially powerful influence of community history. In the case of reproductive behavior at times of fertility transition, the history of health and family planning provision can be especially influential in determining whether change starts relatively early or relatively late and whether change proceeds rapidly or slowly. The placement of health and family planning services is the outcome of an altogether different set of forces, following a logic that is primarily political and bureaucratic and may have little to do with community social organization. Hence when considering the intercommunity pattern of diffusion of new fertility-regulation practices, one must take account of both local social organization and the history of service provision. This general conclusion-that explanatory theory must balance social organization with historical circumstances - emerges from our analysis of variation among small localities. We suspect that the same conclusion applies to comparative historical research on fertility transition at the national level. Undoubtedly variables such as mortality decline, schooling, and income are determinants of the timing and pace of fertility transition; these occupy the place of social organization in this analysis. But the stance of political leaders and the effectiveness of health and family planning programs may have substantial bearing on whether transition starts early or late, and whether it proceeds slowly or rapidly.

\section{NOTES}

This paper draws on materials collected under the project "Diffusion of Fertility Behavior," a collaboration between the University of Cape Coast (Ghana) and the Population Council (United States). The project is supported by awards from the Rockefeller Foundation and the National Institutes of Health (R01 HD34524).

1 The Asafohene are heads of the traditional army, organized to defend the chiefs and community members against external aggression.

2 Discussion of the age at entry into marriage is deferred until the section on community variation in reproductive behavior, because the timing of marriage is an important direct determinant of fertility levels. 
3 To give some rough notion of the density of organizations, the population sizes of the six communities according to the census that we carried out in 1998 were as follows: Abuesi 2,494; Amanfro 858; Brenu 1,211; Frami 1,226; Komfoeku 2,106; Tubaman 1,159. The relatively larger number of organizations in Abuesi and Komfoeku (Table 2) is to be expected, given their far larger population sizes. Perhaps most striking is the large number of organizations in Amanfro in relation to its population size.

\section{REFERENCES}

Blanc, Ann K. and Steve Grey. 2000. Greater Than Expected Fertility Decline in Ghana: An Examination of the Evidence. Calverton, MD: Macro International Inc. and National Population Council Secretariat (Ghana).

Bourdieu, Pierre and Loïc Wacquant. 1992. An Invitation to Reflexive Sociology. Chicago: University of Chicago Press.

Caldwell, John C. 1982. Theory of Fertility Decline. New York: Academic Press.

Casterline, John B. 2001a. "The pace of fertility transition: national patterns in the second half of the twentieth century," in Rodolfo A. Bulatao and John B. Casterline (eds.), Global Fertility Transition. Supplement to Population and Development Review 27: 17-52.

_ 2001b. "Diffusion processes and fertility transition: Introduction," in John B. Casterline (ed.), Diffusion Processes and Fertility Transition. Washington, DC: National Academy Press, pp. 1-38.

Coleman, James S. 1988. "Social capital in the creation of human capital," American Journal of Sociology 94: S95-S120.

—. 1990. Foundations of Social Theory. Cambridge, MA: Harvard University Press.

Fortes, Meyer. 1949. The Web of Kinship among the Tallensi. London: Oxford University Press.

Ghana Statistical Service (GSS) and Macro International (MI). 1999. 1998 Ghana Demographic and Health Survey. Calverton, MD: GSS and MI. 
Granovetter, Mark. 1973. "The strength of weak ties," American Journal of Sociology 78(6): 1360-1380.

Kohler, Hans-Peter, Jere R. Behrman, and Susan Cotts Watkins. 2001. "The density of social networks and fertility decisions: Evidence from South Nyanza District, Kenya," Demography 38(1): 43-58.

Lesthaeghe, Ron J. (ed.). 1989. Reproduction and Social Organization in sub-Saharan Africa. Berkeley: University of California Press.

Lorimer, Frank. 1954. Culture and Human Fertility-A Study of the Relation of Cultural Conditions to Fertility in Non-industrial and Transitional Societies. Paris: UNESCO.

Montgomery, Mark R. and John B. Casterline. 1998. "Social networks and the diffusion of fertility control,” Policy Research Division Working Paper no. 119. New York: Population Council.

Narayan, Deepa and Lant Pritchett. 1999. "Cents and sociability: Household income and social capital in rural Tanzania," Economic Development and Cultural Change 47(4): 871-898.

National Research Council (NRC). 1993. Factors Affecting Contraceptive Use in SubSaharan Africa. Washington, DC: National Academy Press.

Portes, Alejandro and Patricia Landolt. 1996. "The downside of social capital," American Prospect (May-June): 18-21, 94.

Rogers, Everett M. 1983. Diffusion of Innovation. New York: Free Press.

Valente, Thomas. 1995. Network Models of the Diffusion of Innovations. Cresskill, NJ.: Hampton Press.

Watkins, Susan Cotts. 1991. “More lessons from the past: Women's informal networks and fertility decline," paper presented at the IUSSP seminar on Fertility in subSaharan Africa, Harare, Zimbabwe, November. 


\title{
POLICY RESEARCH DIVISION WORKING PAPERS
}

\author{
Recent Back Issues
}

133 Mary Arends-Kuenning and Sajeda Amin, "The effects of schooling incentive programs on household resource allocation in Bangladesh."

134 John Bongaarts and Charles F. Westoff, "The potential role of contraception in reducing abortion."

135 John B. Casterline and Steven W. Sinding, "Unmet need for family planning in developing countries and implications for population policy."

*136 Carol E. Kaufman, Thea de Wet, and Jonathan Stadler, "Adolescent pregnancy and parenthood in South Africa."

*137 Valerie L. Durrant and Zeba A. Sathar, "Greater investments in children through women's empowerment: A key to demographic change in Pakistan?"

138 Sajeda Amin, Alaka Malwade Basu, and Rob Stephenson, "Spatial variation in contraceptive use in Bangladesh: Looking beyond the borders."
139 Geoffrey McNicoll, "Managing population-environment systems: Problems of institutional design."

140 Barbara S. Mensch, Barbara L. Ibrahim, Susan M. Lee, and Omaima ElGibaly, "Socialization to gender roles and marriage among Egyptian adolescents."

141 John Bongaarts and Elof Johansson, "Future trends in contraception in the developing world: Prevalence and method mix."

*142 Alaka Malwade Basu and Sajeda Amin, "Some preconditions for fertility decline in Bengal: History, language identity, and an openness to innovations."

143 Zeba Sathar, Cynthia B. Lloyd, Cem Mete, and Minhaj ul Haque, "Schooling opportunities for girls as a stimulus for fertility change in rural $\mathrm{Pa}-$ kistan." 
144 John Bongaarts, "Household size and composition in the developing world."

145 John B. Casterline, Zeba A. Sathar, and Minhaj ul Haque, "Obstacles to contraceptive use in Pakistan: A study in Punjab."

146 Zachary Zimmer, Albert I. Hermalin, and Hui-Sheng Lin, "Whose education counts? The impact of grown children's education on the physical functioning of their parents in Taiwan."

147 Philomena Nyarko, Brian Pence, and Cornelius Debpuur, "Immunization status and child survival in rural Ghana."

*148 John Bongaarts and Zachary Zimmer, "Living arrangements of older adults in the developing world: An analysis of DHS household surveys."

149 Markos Ezra, "Ecological degradation, rural poverty, and migration in Ethiopia: A contextual analysis."
150 Cynthia B. Lloyd, Sahar El Tawila, Wesley H. Clark, and Barbara S. Mensch, "Determinants of educational attainment among adolescents in Egypt: Does school quality make a difference?"

151 Barbara S. Mensch, Paul C. Hewett, and Annabel Erulkar, " The reporting of sensitive behavior among adolescents: A methodological experiment in Kenya."

152 John Bongaarts, "The end of the fertility transition in the developed world."

153 Mark R. Montgomery, GebreEgziabher Kiros, Dominic Agyeman, John B. Casterline, Peter Aglobitse, and Paul Hewett, "Social networks and contraceptive dynamics in southern Ghana."

*154 Paul C. Hewett and Mark R. Montgomery, "Poverty and public services in developing-country cities."

\footnotetext{
* No longer available
} 
155 Zachary Zimmer, Linda G. Martin, and Ming-Cheng Chang, "Changes in functional limitations and survival among the elderly in Taiwan: 1993, 1996, and 1999."

156 John Bongaarts and Griffith Feeney, "How long do we live?"

157 Zachary Zimmer and Sovan Kiry Kim, "Living arrangements and socio-demographic conditions of older adults in Cambodia."

158 Geoffrey McNicoll, "Demographic factors in East Asian regional integration."

159 Carol E. Kaufman, Shelley Clark, Ntsiki Manzini, and Julian May, "How community structures of time and opportunity shape adolescent sexual behavior in South Africa."

160 Julia Dayton and Martha Ainsworth, "The elderly and AIDS: Coping strategies and health consequences in rural Tanzania."

161 John Bongaarts, "The end of the fertility transition in the developing world."
162 Naomi Rutenberg, Carol E. Kaufman, Kate Macintyre, Lisanne Brown, and Ali Karim, "Pregnant or positive: Adolescent childbearing and HIV risk in South Africa."

163 Barbara S. Mensch, Wesley H. Clark, and Dang Nguyen Anh, "Premarital sex in Vietnam: Is the current concern with adolescent reproductive health warranted?"

164 Cynthia B. Lloyd, Cem Mete, and Zeba A. Sathar, "The effect of gender differences in primary school access, type, and quality on the decision to enroll in rural Pakistan."

165 Kelly Hallman, Agnes R. Quisumbing, Marie Ruel, and Bénédicte de la Brière, "Childcare, mothers' work, and earnings: Findings from the urban slums of Guatemala City."

166 Carol E. Kaufman and Stavros E. Stavrou, “'Bus fare, please': The economics of sex and gifts among adolescents in urban South Africa."

167 Dominic K. Agyeman and John B. Casterline, "Social organization and reproductive behavior in southern Ghana." 